\title{
Relationship between religiosity and depression of older persons in Bangladesh
}

\begin{abstract}
Older persons are vulnerable to the effects of various psychological problems. The most frequent problem among older persons is depression, which may negatively affect their lives. Religiosity is also a common feature of older persons. The purpose of this study is to investigate the relationships between older persons' depression and religiosity in two southern districts in Bangladesh. Data were collected from 280 older persons using the Geriatric Depression Scale (GDS-10) and Strength of Religious Faith Scale (SRFS). Descriptive and correlational statistics were used to analyze depression and religiosity data. Results show that religiosity is significantly and positively related to depression. The identification of intervention programs for the screening of depression, with a view to reducing depression's consequences via the promotion of religiosity, is recommended.
\end{abstract}

Keywords: depression, older persons, religiosity
Volume 2 Issue 5 - 2017

\section{Mohammad Abbas Uddin}

Nursing Department, District Hospital, Bangladesh

Correspondence: Mohammad Abbas Uddin, Nursing Department, District Hospital, Lakshmipur, Bangladesh, Email uabbas9@gmail.com

Received: October 26, 2017 | Published: December 05, 2017
Abbreviations: M, mean; SD, standard deviation; TK, bangladeshi currency; GDS, geriatric depression scale; SRFS, strength of religious faith scale

\section{Introduction}

Depression is defined as changes in cognition and mood and loss of interests. Older persons are vulnerable to the effects of depression, which include various physical and social problems. These include problems carrying out activities of daily living ${ }^{1}$ decreased physical, cognitive and social functioning; and greater self-neglect. ${ }^{2}$ Generally, depressive symptoms can exacerbate health outcomes. ${ }^{3}$ In Bangladesh, older persons (those aged 60 or above) had a 2.79 times higher risk of depression than middle-aged persons (those aged 40-59). ${ }^{4}$

Older persons show a greater preference for religious activities than younger people. Religiosity is defined as perceptions of religious beliefs, worship, and prayer. ${ }^{5}$ Religious involvement appears to minimize unsafe behaviors, act as a buffer against stress, provide social support, and help people to find meaning in life ${ }^{6}$ Religiosity can provide a positive and hopeful attitude about life and illness, as well as a sense of meaning and purpose in life. As a result, religiosity affects health behaviors and social and family relationships and is linked to a greater capacity to cope with illness and disability. ${ }^{7}$ Religiosity has been associated with lower occurrence of mental problems ${ }^{8}$ and fewer depressive symptoms. ${ }^{9}$ Religiosity has a beneficial impact on depression. ${ }^{10}$ Thus, religiosity may be an influential factor on older persons' depression. It has been previously demonstrated that religious engagement did not differ between depressive and nondepressive subgroups. ${ }^{11}$ However, that study investigated Catholic older persons. Differences in religious beliefs and religiosity may lead to different results for Islamic older persons. The purpose of this study was to investigate relationships between depression and religiosity among Islam believers. The results may foster greater understanding of Muslim religiosity and the role it may play in support of depressive older persons.

\section{Data and methods}

The study data were collected between September 2015 and
January 2016 from 280 older persons living in villages in two southern districts of Bangladesh. Participants were selected by specific inclusion criteria. They had to be aged between 60 to 75 years, free from cognitive impairment, and free from severe chronic illness. Data were collected via a demographic data form, the GDS- $10,{ }^{12}$ and the SRFS. ${ }^{5}$ The GDS-10 consists of ten items:
i. Feeling satisfied with life
ii. Reduction of activities
iii. Feeling empty
iv. Being afraid of bad things
v. Feeling happy
vi. Feeling helpless
vii. Memory problems
viii. Feeling full of energy
ix. Feeling hopeless and
x. Judgment

Each item's score was either 0 (no depression) or 1 (depression). The potential total scores ranged from 0to10. A total score between 0 and 4 is considered to indicate no depression and a score of 5 or more considered to indicate depression. ${ }^{13}$ The SRFS consists of three domains: religious belief, worship, and prayer. These were assessed with an eleven-item scale. First, participants were asked to rate their level of agreement with eight reasons that religion might be important to them. The items were:

a. It helps me to cope with life events.

b. It answers many questions about the meaning of my life.

c. It teaches me how to deal with life.

d. It provides practice for dealing with life's challenges and events.

e. It helps others. 
f. It helps me deal with bad things.

g. It gives me guidance and peace of mind.

h. It helps me make serious decisions.

Secondly, participants were asked to rate their level of agreement with three possible purposes of prayer:
i. Satisfaction
ii. Happiness
iii. Reducing stress

Each item was assessed on a five-point Likert, ranging from 1 (strongly disagree) to 5 (strongly agree). Total scores ranged between 11 and 55, with higher scores reflecting higher levels of strength of religious faith. In this study, the reliability of the GDS-10 and SRFS were determined by Cronbach's Alpha Coefficient, and the values found were .78 and 97 . These were considered satisfactory.

Secondary data were analyzed using a statistical program (SPSS 13.0). Descriptive statistics, including frequency, percentage, mean and standard deviation, were used to analyze demographic, depression and religiosity data. Spearman's Rho was used to identify the relationship between depression and religiosity.

\section{Results}

The majority $(85.4 \%)$ of older persons was between 60 and 70 years old. $50.4 \%$ were male and $49.60 \%$ were female. The majority $(80.0 \%)$ were married, and $55.0 \%$ were illiterate. $53.2 \%$ of the sample lived in a nuclear type of family, and most (71.8\%) reported their family's monthly income as between 300 and 6,000 Taka (80 Taka $=$ 1\$) (Tables 1-4).

Table I Demographic characteristics of older persons $(n=280)$

\begin{tabular}{|c|c|c|}
\hline Characteristics & Categories & Frequency (\%) \\
\hline \multirow[t]{2}{*}{ Age $(M=65.8 \mathrm{I}, \mathrm{SD}=4.37)$} & 60 - 70 years & $239(85.4)$ \\
\hline & 7I - 75 years & $4 I(14.6)$ \\
\hline \multirow[t]{2}{*}{ Gender } & Male & |4| (50.4) \\
\hline & Female & $139(49.6)$ \\
\hline \multirow[t]{2}{*}{ Marital status } & Married & $224(80.0)$ \\
\hline & Widow & $56(20.0)$ \\
\hline \multirow[t]{2}{*}{ Education level } & Illiteracy & I54 (55.0) \\
\hline & Literate & $126(45.0)$ \\
\hline \multirow[t]{2}{*}{ Employment status } & Employed & 232 (82.9) \\
\hline & Unemployed & $48(17.1)$ \\
\hline \multirow[t]{2}{*}{ Type of family } & Nuclear & 149 (53.2) \\
\hline & Extended & $|3|(46.8)$ \\
\hline \multirow[t]{2}{*}{$\begin{array}{l}\text { Family monthly income } \\
{[\text { I USD }=80 \text { Taka }]}\end{array}$} & 300 - 6,000 Taka & 201 (7I.8) \\
\hline & 6,001 - 20,000Taka & $79(28.2)$ \\
\hline
\end{tabular}

Table 2 Depression of older persons $(n=280)$

\begin{tabular}{lll}
\hline Variable & Categories & Frequency (\%) \\
\hline Depression & No depression & $44(15.7)$ \\
& Having depression & 236(84.3)
\end{tabular}

The majority (84.3\%) of older persons reported having depression. Only $15.7 \%$ of the older persons reported no depression

Table 3 Religiosity of older persons $(n=280)$

\begin{tabular}{llll}
\hline Variable & Mean (M) & Standard deviation(SD) & Level \\
\hline Religiosity & $52.5 \mathrm{I}$ & 3.49 & High
\end{tabular}

Table 4 Relationship between religiosity and depression of older persons $(n=280)$

\begin{tabular}{ll}
\hline Variable & Depression \\
\hline Religiosity & $.4 I^{* *}$
\end{tabular}

$* * p<.01$

Older persons' religiosity was significantly and positively related to their depression $(r=.40, p<.01)$

\section{Discussion}

Almost all participants reported having depression and a high level of religiosity. Religiosity was significantly and positively related to depression. As older persons' depression increased, their religiosity increased. One explanation is that older persons face various physical and mental and social problems due to declining physical strength, the effects of diseases, and inadequate social support. As a result, they may lead a stressful life which may cause depression. All participants were Muslim. They could practice their religiosity freely at their villages' religious institutes. $55.00 \%$ of participants were illiterate and unable to read their religious book, the Quran, which is written in Arabic. Therefore, they depended on religious leaders. It is hypothesized that older persons may sometimes have received inadequate information from these leaders. However, older persons also used their religiosity to alleviate depression. This study's results are consistent with another study. ${ }^{11}$ It found that depressive people increase their religiosity to achieve better health expectations. In addition, dimensions of religiosity, such as organizational religiosity, have previously been significantly associated with depressive symptoms. ${ }^{14}$ However; those studies investigated non-Muslims and measured religiosity with different instruments.

\section{Conclusion}

Almost all participants reported having depression and a high level of religiosity. Religiosity was significantly and positively related to depression. These results may be useful for clinicians and health care providers and may support them in the development of strategies for assessing and preventing older persons' depression and promoting the use of religiosity in the southern districts of Bangladesh. They may also be relevant to other settings, particularly Muslims in developing countries.

\section{Ethical Considerations}

Permission was obtained from the proper district level health authority, the study participants, and SRFS developer 


\section{Acknowledgements}

The author was pleased to district level health authority for data collection permission. The author also pleased to the study participants for their kind support.

\section{Conflict of interest}

No conflict of interest has been declared by the author.

\section{References}

1. RD Dhara, YA Jogsan. Depression and psychological well-being in old age. Journal of Psychology and Psychotherapy. 2013;3:117.

2. DG Blazer. Depression in late life: Review and commentary. Journals of Gerontology. Biological Sciences and Medical Sciences. 2003;58(3):249-265.

3. World Health Organization. Depression. 2012.

4. J Das, FD Farzana, F Ferdous, et al. Factors associated with elderly depression among rural Bangladeshi individuals. American Journal of Psychiatry and Neuroscience. 2014;2(1):1-7.

5. Achour M, Grine F, Mohd Nor MR, et al. Measuring religiosity and its effects on personal well-being: A case study of Muslim female academicians in Malaysia. Journal of Religion and Health. 2014;54(4):984-997.

6. HG Koenig, A Büssing. The Duke University Religion Index: A five-item measure for use in epidemiological studies. Religions. 2010;1:178-185.
7. DB Kaplan, BJ Berkman. Religion and spirituality in the elderly. Columbia; 2013.

8. RM Bonelli, HG Koenig. Mental disorders, religion and spirituality 1990 to 2010: A systematic evidence-based review. Journal of Religion and Health. 2013;52(2):657-673.

9. Sternthal MJ, Williams DR, Musick MA, et al. Depression, anxiety, and religious life: A search for mediators. Journal of Health and Social Behavior. 2010;51(3):343-359.

10. Taylor RJ, Chatters LM, Abelson JM. Religious involvement and DSMIV 12-month and lifetime major depressive disorder among African Americans. J Nerv Ment Dis. 2012;200(10):856-862.

11. M Pokorski, A Warzecha. Depression and religiosity in older age. European Journal of Medical Research. 2011;16(9):401-406.

12. Yesavage JA, Brink TL, Rose TL, et al. Development and validation of a geriatric depression screening scale: A preliminary report. $J$ Psychiatr Res. 1983;17(1):37-49.

13. Almeida OP, Almeida SA. Short versions of the Geriatric Depression Scale: A study of their validity for the diagnosis of a major depressive episode according to ICD-10 and DSM- IV. Int J Geriatr Psychiatry. 1999;14(10):858-865.

14. Solomon MD. Religiosity, spirituality and depressive symptoms in older adults in an active living community. Graduate Theses and Dissertations, USA; 2014. 